\title{
Surgical treatment of primary malignant tumors of the sacrum
}

Péter Pál Varga*, Zsolt Szövérfi, Aron Lazary

National Center for Spinal Disorders, Budapest, Hungary

National Center for Spinal Disorders, Kiralyhago u. 1-3., Budapest, Hungary, H-1126

${ }^{*}$ Corresponding author:

Peter Paul Varga

Phone: +36-1-8877900

Fax: $+36-1-8877987$

E-mail: vpp@bhc.hu 


\section{Abstract}

\section{Objectives}

The objective of the authors was to provide an up-to-date review about the epidemiology, diagnosis and surgical management of the malignant primary sacral tumors.

\section{Methods}

A PubMed search was conducted using a combination of the following items: (("Spinal Neoplasms"[Mesh]) AND "Sacrum"[Mesh]) NOT ("Metastasis" OR "Metastases" OR "Benign"). The literature review and the author's own surgical experiences were used to assess the current treatment strategies of the malignant sacral tumors.

\section{Results}

Twenty case series were identified, which studies discuss in detail the surgical strategies, the postoperative complications, the functional and onclolgic outcome, the recurrence free and the disease specific survival of this rare patient category.

\section{Discussion}

Sacral tumors are rare pathologies. Their management generates a complex medical problem, as they usually are diagnosed in advanced stages with extended dimensions involving the sacral nerves and surrounding organs. The evaluation and complex treatment of these rare tumors require a multidisciplinary approach, optimally at institutions with comprehensive care and experience. Although conventional oncologic therapeutic methods should be used as neoadjuvant or adjuvant therapies in certain histological types, en bloc resection with wide surgical margins is essential for long-term local oncologic control. This is often technically difficult to achieve, as just a few centers in the world perform sacral tumor surgeries on a regular basis, and have enough wide experience. Therefore international cooperation and organization of multicenter tumor registries are essential to develop evidence based treatment protocols.

Keywords: sacral tumor, complication, neoplasm, outcome, sacrum, sacrectomy 


\section{Introduction}

Primary malignant tumors of the sacrum are rare ${ }^{1}$. The majority of them are low-grade malignancies like chordoma and chondrosarcoma, characterized by slow growth and long standing nonspecific initial symptoms ${ }^{2}$. In contrast, Ewing sarcoma, osteosarcoma and other high-grade neoplasms may have more aggressive and dramatic presentation ${ }^{3}$.

The effective treatment of these rare conditions requires a multidisciplinary team, including oncologists, radiologists, radiotherapists and spine surgeons ${ }^{4}$. The fundamental step of the diagnostic process (preceded by proper clinical, morphological and functional studies, including laboratory tests) is the biopsy $y^{5}$. After establishing the pathological diagnosis, the team should plan the proper structure of the multimodular-, histotype- and patient specific treatment ${ }^{4}$. Due to the permanent progress in oncology, the therapeutic strategies in some tumor types are changing dramatically. For example, a decade ago the treatment of choice in Ewing sarcoma was surgical intervention. Today, due to the effective drug development strategies, the surgical intervention has become a last step, used only in some cases after ineffective chemotherapy ${ }^{3}$. In chordomas, proton and carbon beam therapy are successfully used in the treatment of clival lesion. However surgery is still the first choice of treatment in the case of large sacrococcygeal chordoma ${ }^{2}$. Similarly, in case of a sacral chondrosarcoma there are no widely accepted and accessible chemo- or radiotherapeutic treatment protocols. Thus en bloc surgical resection is the eligible curative treatment method ${ }^{2}$. In most cases wide resection of these tumors is the only option to achieve local control and long term survival, however adjuvant radiotherapy can multiply the disease-free survival ${ }^{6}$. The local recurrence rate after surgery, due to the complex anatomy of the sacral region and the difficulty to achieve tumor free margins, is relatively high ${ }^{7}$.

The different surgical treatment methods of sacral tumors have shown a similarly fast evolution. The spine tumor centers that treat a fair number of cases have contributed to build international databases and to develop the basic surgical principles ${ }^{48}$. The objective of the present paper is to give an updated literature overview about the surgical management of the primary malignant tumors of the sacrum.

\section{Epidemiology of primary malignant sacral tumors}

Spinal malignant primary bone tumors are rare, they are accounting for less than $5 \%$ of all osseous neoplasms, and less than $0.2 \%$ of all cancers ${ }^{9}$. According to the results of large scale population registries, the incidence of primary sacral tumors varies between $32 \%$ and $71 \%$ of all primary spinal tumors $^{10,11}$. The most common primary malignant tumors of the sacrum are chordoma and sacral sarcomas like chondrosarcoma, osteosarcoma and Ewing sarcoma ${ }^{12}$.

Chordoma is the most common primary spinal tumor with an overall incidence of 0.08 per 100,000 individuals accounting for $40 \%$ of all primary sacral tumors ${ }^{13}$. The male:female prevalence ratio is 2:1 with an increasing incidence after the fourth decade ${ }^{14}$. These lesions arise from notochordal remnants within the vertebral bodies and sacrum and are considered slow growing, locally aggressive lesions. Median overall survival is estimated to 7.7 years in the Surveillance, Epidemiology, and End Results (SEER) Program of the National Cancer Institute (1973-2009) ${ }^{13}$. 
Chondrosarcoma has an overall incidence of 0.5 per 100,000 per year, although its sacral localization is below $5 \%$ of all cases ${ }^{15}$. It is more common in males aged between $30-70$ years, with a peek in the fifth decade. Chondrosarcoma may arise as primary tumor or as secondary transformation of an osteochondroma or enchondroma ${ }^{16}$.

Ewing's sarcoma and the PNET-group are the second most frequent primary malignant bone cancers in children and adolescents with an overall incidence is less than 0.2 per 100,000 per year ${ }^{17}$. They involve the spine primarily in 3 to $10 \%$ of cases ${ }^{18}$, sacrum being the most involved spinal level ${ }^{19}$. The male female ratio for Ewing's sarcoma is 3:1, it affects young people between 5 to 30 years. Seventy five percent of this tumor occurs in the first two decade ${ }^{18}$.

Osteosarcoma is the most common primary bone tumor but rarely affects the spine ${ }^{20}$, accounting for only $4 \%$ of primary sacral tumors ${ }^{21}$. Many of the osteosarcomas that occur in the sacrum are secondary to degeneration of Paget disease ${ }^{18}$.

\section{Clinical appearance and diagnosis}

Each patient suspected of having a primary sacral tumor should undergo a thorough local and systemic work-up. Imaging studies give information about the extension of the tumor, but the fundamental component of the staging procedure is the histopathological examination.

The clinical presentation of sacral tumors depends mainly on the anatomical location of the lesion within the sacrum and it is influenced by the aggressiveness of the neoplasm ${ }^{22}$. Majority of the patients initially report low back or buttock pain but a painless visible sacral mass can also be the first sign of the disease. The pain is secondary due to mass effect and to the erosion and impingement of the surrounding structures ${ }^{6}$. Pain may be present with or without neurologic symptoms. Numbness, loss of sensation, decreased reflexes, sphincter dysfunction or motor deficit can be also the first sign. A specific concordance of sensory, motor, and vegetative symptoms may suggest the development of cauda equina syndrome requiring urgent surgical intervention ${ }^{23}$. A large presacral mass may be palpable on digital rectal examination, and due to obstruction can cause constipation. Invasion of the sacroiliac joint can cause discomfort or even pain during sitting or walking. Weight loss, general weakness and other general neoplastic signs are the characteristic of metastatic lesions rather than primary sacral tumors ${ }^{1}$.

Plain radiography is often the first imaging modality performed but it has limited sensitivity ${ }^{18}$. Amorosa et al. demonstrated in their study in patients with proven sacral pathological lesions that the accuracy of the initial radiologic evaluation can be as low as $17 \%{ }^{24}$. More accurate visualization of the region can be obtained by using computerized tomography (CT) or magnetic resonance imaging (MRI). In most cases, both should be performed, because of the different characteristics of the two methods ${ }^{6}$. CT scans show well the osseous relations, as well as intratumoral calcification. Rectal or venous contrast can be administered to visualize the involvement of pelvic structures ${ }^{6}$. The possibility of three-dimensional reconstruction is a great advantage of the CT scan. However, MRI is the imaging modality of choice in the case of sacral neoplasms, because it allows a clearer definition of soft tissue involvement. The combination of T1- and T2-weighted imaging is suitable to define tumor size, location and other characteristic features and may yield enough information for presumptive diagnosis $^{6}$. Bone scintigraphy is widely used to determine whether the lesion is monostotic or polyostotic, and to search for bone metastases ${ }^{25}$. Most primary sacral tumors have an increased 
uptake on bone scan, but lacks specificity to identify the nature of an abnormality. A more advance form of scintigraphy is the SPECT, which has been shown to increase the diagnostic usefulness of bone scan by improving its specificity and sensitivity. It has a superior ability to detect lesions otherwise missed on CT or MRI examinations ${ }^{26}$. Although, some sacral tumor types have specific CT or MRI signs (Table 1.) ${ }^{14,16,18,27}$, the imaging process is only appropriate to describe the anatomic situation and the dimensions of the tumor, and to provide a definitive diagnosis.

The final diagnosis of primary sacral tumor can be made after an accurate histological examination. Open biopsy is considered to be the so-called gold standard for the diagnosis of bone lesions, with $98 \%$ accuracy ${ }^{28}$. Recently, percutaneous CT guided needle biopsy has gained popularity, showing a good accuracy with a less invasive procedure. A meta-analysis of spinal percutaneous biopsies estimated its accuracy to $92 \%{ }^{29}$. In a systematic review Yamazaki et al. assessed the effect of incisional biopsy on the surgical outcome, and found that incisional biopsy significantly increases the risk of recurrence of primary spine tumors ${ }^{30}$.

\section{Limitation of the non-surgical therapy}

The primary goal of the therapeutic process is to be curative. Treatment options of primary malignant sacral tumors should be discussed by a multidisciplinary team, including oncologists, radiologists, radiotherapists and spine surgeons. This special group should decide on the strategy of the treatment, selecting the optimal combination of conventional chemo- or raditherapeutic modalities, as well as to indicate the role of the surgical intervention. The decision depends on the location, extent and biological aggressiveness of the lesion, and it is influenced by the general condition of the patient and by the accessibility to the highly sophisticated medical interventions.

Majority of primary sacral tumors, including chordoma and chondrosarcoma, are relatively resistant to the conventional radio- or chemotherapy, although radiotherapy can be used as an adjunctive treatment in case of intralesional surgical resection ${ }^{6}$. In the case series of York et al. adjuvant radiotherapy tripled the disease-free survival time in chordomas ${ }^{31}$. Biologically higher doses are achievable with charged particle beam radiation therapies (i.e., protons, helium, neon, and carbon ions). Due to increased effective doses and the lower incidence of side effects, carbon-ion radiotherapy ${ }^{32,33}$, and high-dose proton/photon therapy ${ }^{34}$, was reported to have better results compared with conventional radiotherapy. In contrast to conventional radiotherapy, where the full dose is delivered to the sacrum, cauda equina and the surrounding soft tissues, intensity-modulated radiation therapy (IMRT), stereotactic radiosurgery and the CyberKnife can deliver a high-dose single fraction to the target tissue sparing most of the adjacent neural or visceral elements ${ }^{35-37}$. The effect of the different radiation therapies can be further enhanced by the utilization of radiosensitizing agents like razoxane $e^{38,39}$.

Chemotherapy has never played a significant role in the treatment of low-grade sacral malignancies. Reports of tumor responses to regimens, including anthracyclines, cisplatin and alkylating agents, are only anecdotal ${ }^{40}$. Recently, medical oncologists have pointed out the apparent sensitivity of chordoma to new molecular-targeted agents like imatinib, cetuximab and gefitinib ${ }^{41}$. Unfortunately these novel drugs are only accessible in clinical studies, and only for patients with unresecteble or metastatic tumors ${ }^{42}$. Chemotherapy is not effective in chondrosarcoma, however new chemotherapeutic agents like pemetrexed or sumantinib are currently evaluated ${ }^{43,44}$. 
A decade ago the treatment of choice in high-grade primary malignant sacral tumors, like Ewing sarcoma and osteosarcoma was surgical intervention ${ }^{3}$. Today, due to the development of novel chemotherapeutic agents the surgical intervention has become the last step. In a systematic review, Sciubba et al. concluded that in the case of spinal Ewing sarcoma and osteosarcoma neoadjuvant chemotherapy and multimodality management offers a significant improvement in local control and long-term survival ${ }^{3}$. Surgery plus modern multidrug chemotherapy has dramatically increased the 5year disease-free survival rate of osteosarcoma patients to $60-70 \%$, and in the case of Ewing sarcoma patients to $80 \%{ }^{45,46}$. Although the treatment of choice of Ewing sarcoma and osteosarcoma is chemotherapy, even with effective chemotherapy, these tumors are rarely cured without surgical resection ${ }^{47,48}$

\section{Surgical classification and planning}

In the mobile spine two staging system are frequently utilized. The Enneking surgical staging system of bone tumors ${ }^{49}$ is widely used for planning the surgery of limb lesions (introducing the concepts (1) intralesional: piecemeal debulking or curettage, (2) marginal: lesion shelled out leaving pseudocapsule or reactive zone, (3) wide: intracompartmental en bloc, and (4) radical: extracompartmental excision). The adoption of this classification in the management of primary spine tumors is difficult because it did not takes in account the epidural compartment, the neurologic implication of sacrificing the spinal cord and roots, and the need for restoring spinal stability ${ }^{50}$. The Weinstein-Boriani-Biagini (WBB) staging system ${ }^{51}$ is a newer classification for spinal tumors developed in 1996 by three international cancer institutions (Rizzoli Institute, Mayo Clinic, and the University of lowa Hospitals and Clinics). The fundamental concept of this system is to spare the spinal cord without compromising the surgical margins. As, the surgeons need to take in consideration other critical structures (including the rectum, cauda equina and iliac vessels), the preservation or reconstruction of the lumbo-pelvic junctions stability, these commonly used staging systems are difficult to apply in sacral tumors ${ }^{52}$. Currently, there are no validated and widely used surgical staging systems which take in account all these issues.

Recently Zhang et al. based on own clinical experience proposed a novel classification system for sacral tumors ${ }^{52}$. The classification system is a combination of the WBB and Enneking tumor staging methods, and contains 16 possible categories. Sacral tumors are divided into 2 major types (above or below $\mathrm{S}-2$ ) and then 4 further subtypes (based on the extension of the tumor in the pelvic cavity: $<5$ $\mathrm{cm}$ or $\geq 5 \mathrm{~cm}$ ). A further subdivision (similar to the WBB system) is then added according to the axial plane anatomy ( 3 zones: anterior sacrum, posterior sacrum, and lateral sacrum). Fehlings listed a number of limitations of this novel system: the study is based on retrospective series, has small number of diverse tumor types, moreover the tumor size, involvement of other organs, and distant metastases, were not considered ${ }^{53}$.

In the planning process of the surgical treatment, the classification described by Fourney at al. (based on the level of nerve root sacrifice) could be useful in the everyday clinical experience ${ }^{54}$. They categorized sacral resections into two groups, midline tumors and eccentric lesions (Table 2.). The midline group included low, middle, and high sacral amputations, total sacrectomy, and hemicorporectomy. In the case of low sacral amputation the resection was performed at the level of the S4 nerve roots, in the case of midsacral amputation the resection was at the S3 nerve roots, and in the case of high sacral amputation at the level of the S2 nerve roots. If the tumor reached the S1 
nerve roots, then total sacrectomy was the treatment of choice. Hemicorporectomy (translumbar amputation) was indicated for localized, aggressive tumors that had spread beyond the sacrum to the lumbar spine. If the tumor was located in unilateral position and the planned resection does not exceeded the midline, they introduced the term "eccentric resection" including tumors overgrowing the sacroiliac joint and penetrating to the pelvic bones or to the extraosseal compartments (Figure 2).

\section{Surgical approach}

En bloc resection of primary malignant sacral tumors can be performed from anterior, posterior, lateral and combined surgical approaches ${ }^{55}$. The decision in the use of the different approaches is depending on the tumor localization and the relationship with the surrounding anatomical structures.

Traditionally, en bloc total and high sacrectomies were performed by using a combined anterior and posterior approach ${ }^{54}$. The anterior approach allowed the surgeon to expose the ventral aspect of the tumor, to identify and dissect the internal iliac vessels and the rectum, and allowed to determine the proper plane of the resection. If needed a rectus flap can be prepared for closure of the large posterior surgical defect (VRAM). The posterior approach was then used for tumor removal and spino-pelvic reconstruction ${ }^{54,55}$. In the case of low and mid sacral resection the en bloc tumor removal was feasible through a posterior approach only ${ }^{56,57}$. Recently, Clarke et al. recommended the use of the posterior-only approach for all sacral tumors that do not extend beyond the lumbosacral junction or invade the pelvic organs ${ }^{58}$. Sherman et al. reported acceptable morbidity after posterior-only sacral tumor en bloc resection ${ }^{59}$. In their prospective observational study on positioning related morbidity only obesity and procedure times greater than ten hours were identified as risk factors. In case when the tumor extends through the sacroilliac joint to the iliac bone the eccentric sacrectomy should be combined with hemipelvectomy ${ }^{54}$. In this case in their opinion the proper surgical approach is the lateral decubitus position ${ }^{60}$.

Another important aspect that should be kept in mind is the inclusion of the biopsy tract in the resection. In case of open and CT-guided biopsies, seeding of the biopsy tract or the surgical field may occur during the procedure. Therefore, the surgeon should be involved into the planning of the biopsy, assuring that the biopsy tract will be excised en bloc with the tumor specimen ${ }^{6}$.

\section{Tumor resection}

To achieve a long-term local oncological control, en bloc resection with wide surgical margins is the optimal technique in the surgical management of the malignant tumors of the sacrum ${ }^{2,30}$. Incomplete tumor resection leads to a fast local regrowth, while intralesional resections imply higher local recurrence rate and decreased survival ${ }^{7,61}$. However en bloc total or partial sacrectomy is an uncommon surgery and has a number of challenging factors, including age, the patient's preoperative general condition, the extension of the tumor, and its relationship with surrounding anatomic structures ${ }^{54}$. Neurological structures infiltrated by the tumor often must be sacrificed to achieve proper local control. Depending on the neurological level of the resection this can lead to lower extremity sensory or motor deficits, as well as bowel or bladder incontinence and sexual dysfunction ${ }^{62}$. Rectal involvement by the sacrococcygeal tumor is not common; in these cases the 
proper en bloc resection should include the rectum, requiring colostomy before sacral resection ${ }^{63}$. Partial or total resection of the piriformis and gluteus muscles or sacroiliac joints is an important factor to achieve proper surgical margins and prevent local recurrence ${ }^{1,64}$. The quality of surgical margins had been recently described as the main prognostic factor for local recurrence ${ }^{7,54,58,65}$. Ruggieri et al. reported that achieving wide resection margins at the initial surgery is the most important predictor of local recurrence and survival?

Fuchs et al. performed sacral resection in 52 chordomas $^{66}$. The surgical approach depended on the level and extent of the lesions, they used posterior approach in twenty-two patients and combined anterio-posterior approach in thirty patients. A wide surgical margin was achieved in $40 \%$ of the patients and 23 patients had local recurrence. The rate of recurrence-free survival was $59 \%$ at five years and $46 \%$ at ten years. The overall survival rates were $74 \%, 52 \%$, and $47 \%$ at five years, ten years, and fifteen years, respectively. They found that the wide surgical margin was the most important predictor of survival and of local recurrence in patients with sacrococcygeal chordoma. They also concluded that the use of a combined anterio-posterior approach increased the likelihood of obtaining a wide margin.

In contrast Clarke et al. assessed 36 consecutive sacral chordoma patients who underwent primary posterior-only en bloc sacral resections ${ }^{58}$. They defined sacral amputation level by the sacral root preservation, thus performing in two cases total, in eight cases high, in nine cases middle, in 12 cases low, and in five cases distal sacrectomy. The surgical margins were marginal in 34 cases and contaminated in two patients. In the two year follow up they found only $20 \%$ of recurrence or distant metastases.

The same principle of posterior only sacral tumor resection is promoted by Angelini et al. ${ }^{67}$. They used a novel technique (modified Osaka Technique) to perform the resection of the sacrum in 13 primary sacral tumor patients. The technique uses a device similar to the modified threadwire saw for sacral osteotomies developed by Tomita and Kawahara ${ }^{68}$, and subsequently modified by Osaka et al. ${ }^{69}$. This new technique allows wide margins with preservation of roots, and reduction in blood loss and operative time. They even indicate this modified posterior-only approach to resections proximal to S3, when there is only minimal invasion of the pelvic and sacroiliac joints. They achieved proximal resection in nine patients and distal in four patients, with wide margins in ten patients, marginal in one, and intralesional in two cases. With a mean follow-up of 35.5 months they reported 9 disease free patients and 4 recurrences.

\section{Stabilization}

If sacral tumor resection spares the sacroiliac joint, lumbo-pelvic stability is considered to be preserved $^{54}$. In cases of high sacral resections where minimum of $50 \%$ of the sacroiliac joint is affected, reconstruction becomes mandatory ${ }^{70}$. Bergh et al. found that $33 \%$ of 18 patients with high sacral amputation suffered fatigue fractures of the sacral remnant ${ }^{61}$. In the experience of Fourney et al. lumbo-pelvic reconstruction was unnecessary after hemisacrectomy when the contralateral sacroiliac joint was intact, and there was no anterior pelvic deficiency ${ }^{54}$. Instrumentation provides good stability until fusion occurs, but biological osseous union is the only reliable method of longterm fixation ${ }^{6}$. However there are no reports in the literature about the long term outcome of the lumbo-pelvic fusion rate after total sacrectomies. 
A wide range of lumbopelvic instrumentations had been used previously for reconstruction after total sacrectomy. In the 1980's, Harrington rod technology and combinations of hooks and wires were chosen for lumbo-pelvic reconstruction ${ }^{71}$. This was followed by the use of the more advanced Cotrel-Dubousset rods and hooks with the sacral bars (or AOplates) ${ }^{72}$. In the 1990's, the pedicle screw-Galveston L-rod construct combination was developed ${ }^{71}$. Beside these reconstruction methods several techniques have been published, including modified Galveston reconstruction ${ }^{73}$, triangular frame reconstruction ${ }^{74}$, sacral-rod reconstruction $(S R R)^{75}$, four-rod reconstruction $(F R R)^{76}$, bilateral fibular flaps reconstruction (BFFR) ${ }^{77}$ and the closed-loop reconstruction ${ }^{57}$.

Because of the risk of infection and hardware failure, some authors have recommended that reconstruction should be avoided even in the case of total sacrectomies. Wuisman et al. reported successful mobilization in five patients more than eight weeks after total sacrectomy without any form of reconstruction ${ }^{78}$. Ruggieri et al. advocates similar principles ${ }^{7,79}$. In their experience, after total sacrectomy, the lumbar spine migrates inferiorly and remains between the ilia. The muscles and scar tissue between the pelvis and spine form a biologic sling eventually stabilizing the spine.

After tumor resection, one of the greatest difficulties is the closure of the large sacrectomy defect. Several reconstructive techniques were used for soft tissue reconstruction to prevent rectal prolapse and wound healing complications. The vertical rectus abdominis myocutaneous flap and gluteus maximus adipomuscular flaps were used with the best functional results by several authors ${ }^{80-83}$.

\section{Outcome}

As sacral tumor surgery is characterized by complex surgical techniques, prolonged operating time and severe bleeding, the likelihood of perioperative complications is high. During the surgery, unplanned nerve root resections, visceral and vascular perforations may occur and intraoperative death is also a possible severe complication. In the early postoperative period the development of different wound or surgical site infections may require additional surgical interventions. Proximity to the perineal region, poor blood supply of the skin flap, the huge cavity and the neural atrophy can increase the chance of wound complications. Infection and wound healing complications are common after the resection of sacral tumors ranging from $25 \%$ to $50 \%$ in the literature (Table 3.$)^{31,54,}$ $58,61,64-67,77,79,84-93$

Ruggieri et al. found a significant correlation between the curative, high sacral resections and the development of wound complications ${ }^{79}$. Their deep wound infection rate after 52 sacrectomies was $44 \%$. In contrast, they had no complication in their series of 27 intralesional sacral GCT resections ${ }^{79}$. Although the majority of the resections were high resections, lumbo-pelvic stabilization was not needed. They did not stabilize even the two patients with total sacral resection because of the risk of major wound complications and considering the acceptable ambulatory status of the patients. Beadel et al. reported similar findings ${ }^{94}$. In 16 patients treated with iliosacral resection for primary tumors the incidence of infection was $43 \%$ (7/16 cases). Comparing the 4 patients who had lumbopelvic reconstruction and the 12 patients without reconstruction, the infection rate was higher in the first group (75\%) than in the latter group (33\%). Recently, Li et al. have published a large series of sacral resections and analyzed the factors associated with wound complications ${ }^{95}$. Of the 387 patients 274 healed uneventfully, and 113 (29.2\%) had wound infection or dehiscence. They found 
that previous irradiation, rectum rupture, younger age, history of diabetes mellitus, large tumor volume, and instrumentation used are risk factors for wound complications.

The planed or incidental resection of the sacral nerve roots results in different degree of neurological deficit. As reported by Stener and Gunterberg impairment of ambulatory ability, sphincter function, and sexual capacity were related to the number of preserved nerve roots ${ }^{96,97}$. The third sacral roots are vital for visceral function, the preservation of the bilateral S2 might result in minor and temporary sphincter dysfunction ${ }^{84}$. Fourney et al. reported that their patients with amputations distal to S3 generally experienced limited deficits, with preservation of sphincter function in the majority and some reduced perineal sensation ${ }^{54}$. Gunterberg et al. found that unilateral sacral root dissection does not have significant consequences ${ }^{96}$. Similarly Fourney et al. published that unilateral resection of sacral roots led to unilateral motor deficits; sphincter control can be either preserved or only partially compromised ${ }^{54}$. Protection of $L 5$ and $\mathrm{S} 1$ nerve roots is important for ambulation. If both S1 roots are sacrificed, there is consistent loss of sphincter control and sexual ability, however, patients with intact $L 5$ nerves, generally are able to walk without external support ${ }^{54}$.

The oncological outcome is associated with the surgical margins. In case of intralesional resections, the local recurrence rate can be as high as $83 \%^{31}$. On the other hand, in en bloc wide resections the local recurrence can be also high ranging between 30 and 60\% (Table 3.). York et al. reported in 1999 15 sacral chordoma cases with wide resection from which eight (53\%) relapsed during the follow up. In the series of Bergh et al. six of 16 patients with wide resection (37\%) experienced local recurrence $^{61}$. Bergh et al. concluded that the initial surgery performed elsewhere, larger tumor size and inadequate surgical margins were adverse prognostic factors for local recurrence. In the caseseries of Fuchs et al., 52 patients had been followed for an average of 7.8 years after operative treatment of sacral chordoma ${ }^{66}$. They had an overall local recurrence rate of $44 \%$ but only one of the 21 wide resection cases relapsed (5\%). The authors reported inadequate margins in $60 \%$ of the patients. The mortality rate was $26 \%, 48 \%$, and $53 \%$ at five, ten, and fifteen years, respectively. Fourney et al., in their series, treated 21 patients with malignant primary sacral tumors ${ }^{54}$. In 13 patients the resection was wide and it was marginal in eight cases. Local recurrence or metastasis occurred in $30 \%$ of the former and $50 \%$ of the latter cases, justifying that despite of the morbidity of a wide resection and the inadequate functional outcome, en bloc resection is essential to achieve long-term disease control.

\section{Conclusion}

Most of the primary tumors of the sacrum are low-grade malignant neoplasm with nonspecific symptoms thus they can reach enormous dimensions before being diagnosed. The complexity of the sacral region further complicates the surgical treatment of these tumors. En bloc resection with wide surgical margins is essential for long-term local oncologic control, even though most of the patients might have significant complications. Considering the rarity of the disease and the complexity of the management, multicenter, prospective studies are required to provide high level of evidence and to develop not only the optimal standard surgical procedures but also the new, adjuvant therapeutic options which are still missing. 


\section{Disclaimer Statements}

Contributors Varga PP: conception and design, drafting of manuscript, critical revision, final approval of manuscript, overall responsibility; Szoverfi Zs: literature search, drafting of manuscript, figures, critical revision; Lazary A: literature search, critical revision.

Funding The research leading to this paper received funding from the OTKA PD 104604 and the Eurospine Task Force Research.

Conflicts of interest None.

Ethics approval No patient data is included in this manuscript and no Institutional Review Board approval is required. 


\section{Figures}

Table 1. Diagnostic characteristics of Malignant Primary Sacral Tumors

\begin{tabular}{|c|c|c|}
\hline Tumor & CT & MR \\
\hline Chordoma & $\begin{array}{l}\text { - Expansive } \\
\text { - } \text { Lytic } \\
\text { - Sclerotic } \\
\text { - Intratumoral calcifications }\end{array}$ & $\begin{array}{l}-\quad \text { T1 hypointense } \\
-\quad \text { T2 hyperintense } \\
-\quad G d^{*} \text { enhancment }\end{array}$ \\
\hline Chondrosarcoma & $\begin{array}{l}\text { - Expansive } \\
-\quad \text { Lytic } \\
- \text { Bone destruction } \\
\text { - } \text { Soft tissue expansion }\end{array}$ & $\begin{array}{l}\text { - } \text { T1 hypontense to isointense } \\
\text { - } \text { T2 hyperintense } \\
\text { - } \quad \text { Gd "rings and arcs" pattern }\end{array}$ \\
\hline Ewing sarcoma & $\begin{array}{l}\text { - } \text { Lytic } \\
\text { - Sclerotic }\end{array}$ & $\begin{array}{l}\text { - } \text { T1 isointense } \\
-\quad \text { T2 isointense to hyperintense } \\
\text { - } \quad \text { Gd enhancment }\end{array}$ \\
\hline Osteosarcoma & $\begin{array}{ll}- & \text { Lytic } \\
- & \text { Destructive } \\
- & \text { Matrix mineralization }\end{array}$ & $\begin{array}{l}-\quad \text { T1 hypointense } \\
\text { - } \quad \text { T2 hyperintense }\end{array}$ \\
\hline
\end{tabular}

*Gd: Gadolinium 
Table 2. Classification of en bloc sacral tumor resections after Fourney ${ }^{54}$

\begin{tabular}{lccc}
\hline Type of Sacrectomy & $\begin{array}{c}\text { Nerve Root(s) } \\
\text { Sacrificed }\end{array}$ & Approach & $\begin{array}{c}\text { Lumbopelvic } \\
\text { reconstruction }\end{array}$ \\
\hline Low & S-4 \& below & Posterior & No \\
Middle & S-3 \& below & Posterior & No \\
High & S-2 \& below & Anterior-posterior & No \\
Total & bilateral S1-5 & Anterior-posterior & Yes \\
Hemicorporectomy & translumbar & Supine-lateral & No \\
Lateral & unilateral (variable) & Lateral & No \\
\hline
\end{tabular}


Table 3.

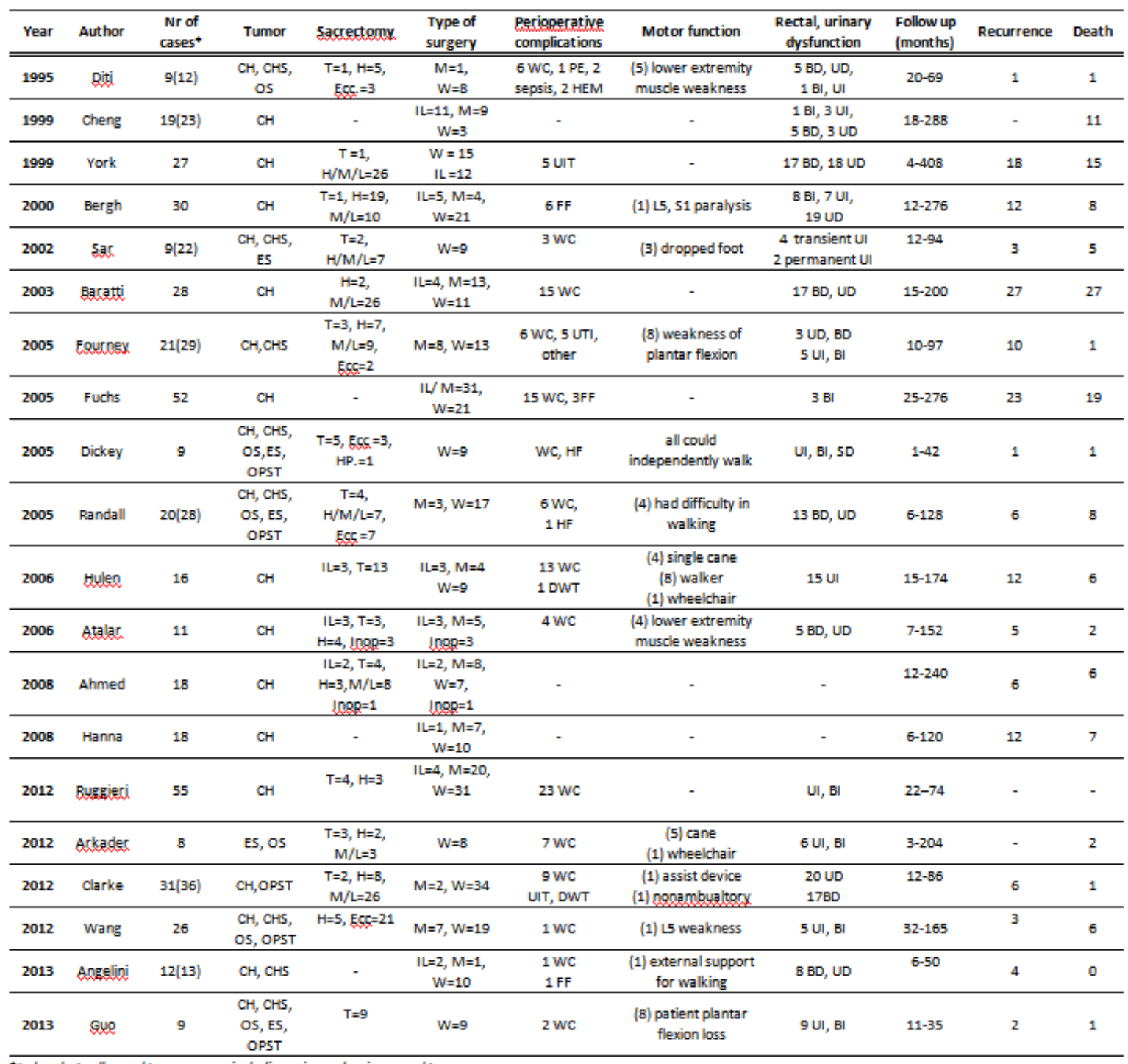

*in brackets all sacral tumar cases, including primary benign sacral tumars

Hystolog: : CH = chordoma, CHS = chondrosarcoma, OS = Osteosarcoma, ES = Ewing sarcoma, OPST = other malignant primary sacral tumors (Malignant eP€ndimepla, Malignant meningioma, Malignant nerve sheath tumor, Synovial sarcoma, Fibrosarcoma, Malignant GCT, Malignant fibrous bustipcytoma, Malignant schwanopoxpa),

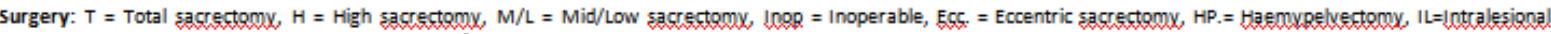
resection, M=Marginal resection, $W=$ Wide resection, |

Complications: $\mathrm{UI}=$ Urinary incontinence, $\mathrm{BI}=\mathrm{BO}$ ewel incontinence, $\mathrm{UD}=$ Urinary disturbance, $\mathrm{BD}=$ Bowel dysfunction, $S \mathrm{D}=$ sexual dysfunction, wC $=$ wound complication, $\mathrm{PE}$ =pulmonary embolism, UIT = urinary tract infection, DWT = Deep wein thrombosis, FF = fatigue fracture, HF =hardware failure 


\section{Figure 1.}

Categorization of sacral resections after Fourney ${ }^{54}$; A. Low sacral amputation - the sacrifice of S4 nerve roots B. Midsacral amputation - the sacrifice of the S3 nerve roots C. High sacral amputation the sacrifice of the S2 nerve roots $D$. Total sacrectomy - the sacrifice of the S1 nerve roots $E$. Hemicorporectomy (translumbar amputation) - for aggressive tumors that had spread beyond the sacrum to the lumbar spine F. Eccentric resection - for tumors that does not exceed the midline
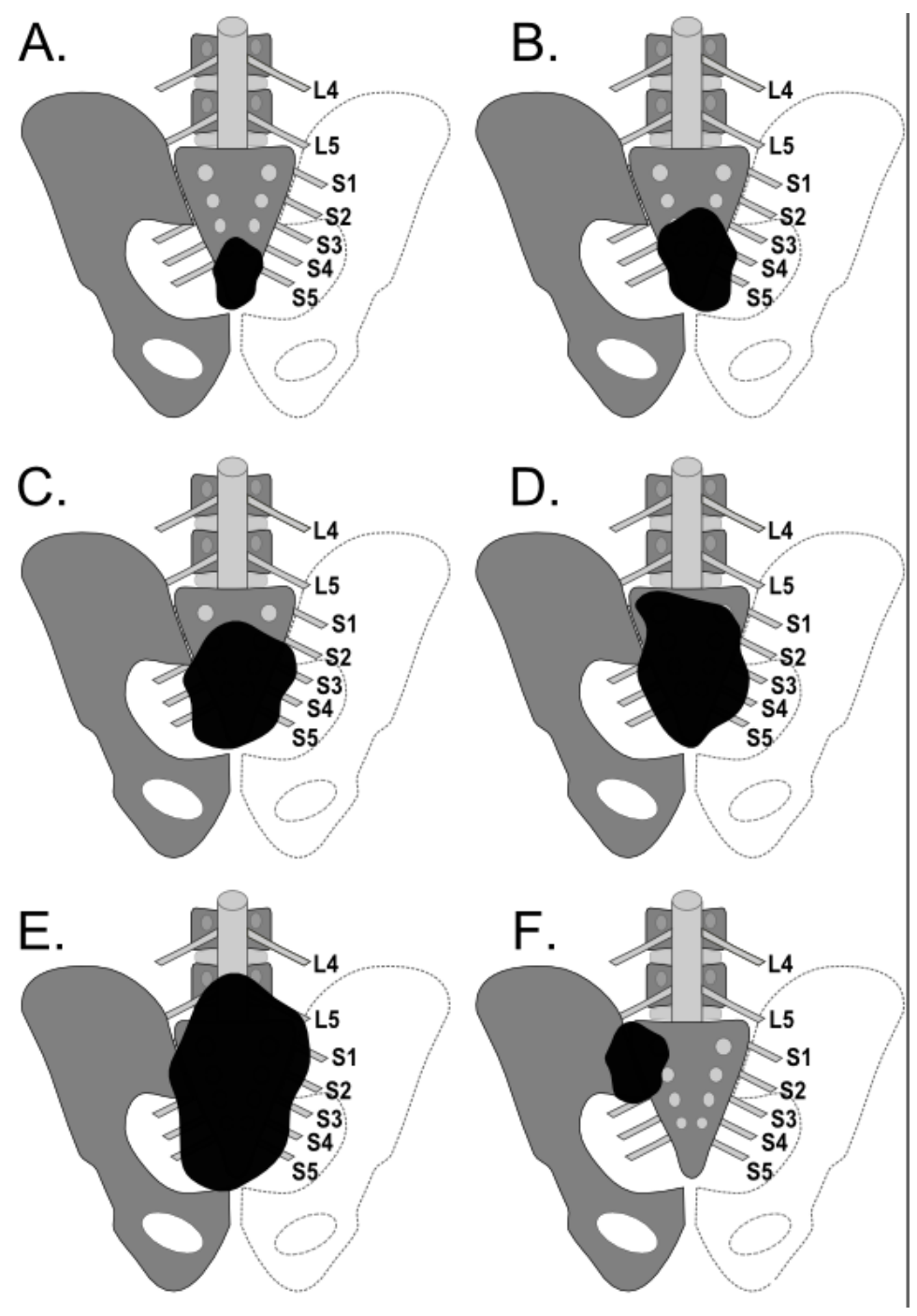


\section{Bibliography}

1. Varga PP, Bors I, \& Lazary A. Sacral tumors and management. Orthop Clin North Am 2009; 40: 105-123, vii

2. Boriani S, Saravanja D, Yamada Y et al. Challenges of local recurrence and cure in low grade malignant tumors of the spine. Spine (Phila Pa 1976) 2009; 34: S48-57

3. Sciubba DM, Okuno SH, Dekutoski MB et al. Ewing and osteogenic sarcoma: evidence for multidisciplinary management. Spine (Phila Pa 1976) 2009; 34: S58-68

4. Sundaresan N, Boriani S, \& Okuno S. State of the art management in spine oncology: a worldwide perspective on its evolution, current state, and future. Spine (Phila Pa 1976) 2009; 34: S7-20

5. Tehranzadeh J, Tao C, \& Browning CA. Percutaneous needle biopsy of the spine. Acta Radiol 2007; 48: 860-868

6. Sciubba DM, Petteys RJ, Garces-Ambrossi GL et al. Diagnosis and management of sacral tumors. J Neurosurg Spine 2009; 10: 244-256

7. Ruggieri $P$, Angelini A, Ussia G et al. Surgical margins and local control in resection of sacral chordomas. Clin Orthop Relat Res 2010; 468: 2939-2947

8. C Fisher, S Boriani, PP Varga et al (2013) A Novel Model for Rare and often Neglected Neoplastic Conditions in Global Spine Congress (Hong Kong).

9. Anonymous (American Cancer Society. Cancer Facts \& Figures 2008. Atlanta: American Cancer Society; 2008.

10. Kelley SP, Ashford RU, Rao AS et al. Primary bone tumours of the spine: a 42-year survey from the Leeds Regional Bone Tumour Registry. Eur Spine J 2007; 16: 405-409

11. Mukherjee D, Chaichana KL, Gokaslan ZL et al. Survival of patients with malignant primary osseous spinal neoplasms: results from the Surveillance, Epidemiology, and End Results (SEER) database from 1973 to 2003. J Neurosurg Spine 2011; 14: 143-150

12. Mukherjee D, Chaichana KL, Adogwa $\mathrm{O}$ et al. Association of extent of local tumor invasion and survival in patients with malignant primary osseous spinal neoplasms from the surveillance, epidemiology, and end results (SEER) database. World Neurosurg 2011; 76: 580-585

13. Smoll NR, Gautschi OP, Radovanovic I et al. Incidence and relative survival of chordomas: The standardized mortality ratio and the impact of chordomas on a population. Cancer 2013:

14. Ropper AE, Cahill KS, Hanna JW et al. Primary vertebral tumors: a review of epidemiologic, histological and imaging findings, part II: locally aggressive and malignant tumors. Neurosurgery 2012; 70: 211-219; discussion 219

15. Giuffrida AY, Burgueno JE, Koniaris LG et al. Chondrosarcoma in the United States (1973 to 2003): an analysis of 2890 cases from the SEER database. J Bone Joint Surg Am 2009; 91: 1063-1072

16. Thornton E, Krajewski KM, O'Regan KN et al. Imaging features of primary and secondary malignant tumours of the sacrum. Br J Radiol 2012; 85: 279-286

17. Esiashvili N, Goodman M, \& Marcus RB, Jr. Changes in incidence and survival of Ewing sarcoma patients over the past 3 decades: Surveillance Epidemiology and End Results data. $J$ Pediatr Hematol Oncol 2008; 30: 425-430

18. Manaster BJ \& Graham T. Imaging of sacral tumors. Neurosurg Focus 2003; 15: E2

19. Ilaslan H, Sundaram M, Unni KK et al. Primary Ewing's sarcoma of the vertebral column. Skeletal Radiol 2004; 33: 506-513

20. Damron TA, Ward WG, \& Stewart A. Osteosarcoma, chondrosarcoma, and Ewing's sarcoma: National Cancer Data Base Report. Clin Orthop Relat Res 2007; 459: 40-47

21. Unni KK (1996) Dahlin's bone tumors: general aspects and data on 11,087 cases (LippincottRaven). 
22. Payer M. Neurological manifestation of sacral tumors. Neurosurg Focus 2003; 15: E1

23. Bagley CA \& Gokaslan ZL. Cauda equina syndrome caused by primary and metastatic neoplasms. Neurosurg Focus 2004; 16: e3

24. Amorosa JK, Weintraub S, Amorosa LF et al. Sacral destruction: foraminal lines revisited. AJR Am J Roentgenol 1985; 145: 773-775

25. Rossleigh MA, Smith J, \& Yeh SD. Scintigraphic features of primary sacral tumors. J Nucl Med 1986; 27: 627-630

26. Gates GF. SPECT imaging of the lumbosacral spine and pelvis. Clin Nucl Med 1988; 13: 907914

27. Llauger J, Palmer J, Amores $S$ et al. Primary tumors of the sacrum: diagnostic imaging. AJR Am J Roentgenol 2000; 174: 417-424

28. Dupuy DE, Rosenberg AE, Punyaratabandhu T et al. Accuracy of CT-guided needle biopsy of musculoskeletal neoplasms. AJR Am J Roentgenol 1998; 171: 759-762

29. Nourbakhsh A, Grady JJ, \& Garges KJ. Percutaneous spine biopsy: a meta-analysis. J Bone Joint Surg Am 2008; 90: 1722-1725

30. Yamazaki T, McLoughlin GS, Patel $\mathrm{S}$ et al. Feasibility and safety of en bloc resection for primary spine tumors: a systematic review by the Spine Oncology Study Group. Spine (Phila Pa 1976) 2009; 34: S31-38

31. York JE, Kaczaraj A, Abi-Said D et al. Sacral chordoma: 40-year experience at a major cancer center. Neurosurgery 1999; 44: 74-79; discussion 79-80

32. Imai R, Kamada T, Tsuji $\mathrm{H}$ et al. Carbon ion radiotherapy for unresectable sacral chordomas. Clin Cancer Res 2004; 10: 5741-5746

33. Combs SE, Kalbe A, Nikoghosyan A et al. Carbon ion radiotherapy performed as re-irradiation using active beam delivery in patients with tumors of the brain, skull base and sacral region. Radiother Oncol 2011; 98: 63-67

34. Park L, Delaney TF, Liebsch NJ et al. Sacral chordomas: Impact of high-dose proton/photonbeam radiation therapy combined with or without surgery for primary versus recurrent tumor. Int J Radiat Oncol Biol Phys 2006; 65: 1514-1521

35. Gibbs IC. Spinal and paraspinal lesions: the role of stereotactic body radiotherapy. Front Radiat Ther Oncol 2007; 40: 407-414

36. Gibbs IC, Kamnerdsupaphon P, Ryu MR et al. Image-guided robotic radiosurgery for spinal metastases. Radiother Oncol 2007; 82: 185-190

37. Gerszten PC, Ozhasoglu C, Burton SA et al. CyberKnife frameless single-fraction stereotactic radiosurgery for tumors of the sacrum. Neurosurg Focus 2003; 15: E7

38. Rhomberg W, Bohler FK, Novak $\mathrm{H}$ et al. A small prospective study of chordomas treated with radiotherapy and razoxane. Strahlenther Onkol 2003; 179: 249-253

39. Rhomberg $\mathrm{W}$, Eiter $\mathrm{H}$, Bohler $\mathrm{F}$ et al. Combined radiotherapy and razoxane in the treatment of chondrosarcomas and chordomas. Anticancer Res 2006; 26: 2407-2411

40. Casali PG, Messina A, Stacchiotti S et al. Imatinib mesylate in chordoma. Cancer 2004; 101 : 2086-2097

41. Stacchiotti S \& Casali PG. Systemic therapy options for unresectable and metastatic chordomas. Curr Oncol Rep 2011; 13: 323-330

42. Stacchiotti S, Longhi A, Ferraresi V et al. Phase II study of imatinib in advanced chordoma. J Clin Oncol 2012; 30: 914-920

43. Mavrogenis AF, Gambarotti M, Angelini A et al. Chondrosarcomas revisited. Orthopedics 2012; 35: e379-390

44. Dallas J, Imanirad I, Rajani R et al. Response to sunitinib in combination with proton beam radiation in a patient with chondrosarcoma: a case report. J Med Case Rep 2012; 6: 41

45. Ta HT, Dass CR, Choong PF et al. Osteosarcoma treatment: state of the art. Cancer Metastasis Rev 2009; 28: 247-263 
46. Grier HE, Krailo MD, Tarbell NJ et al. Addition of ifosfamide and etoposide to standard chemotherapy for Ewing's sarcoma and primitive neuroectodermal tumor of bone. $\mathrm{N}$ Engl J Med 2003; 348: 694-701

47. Jaffe N, Carrasco H, Raymond $\mathrm{K}$ et al. Can cure in patients with osteosarcoma be achieved exclusively with chemotherapy and abrogation of surgery? Cancer 2002; 95: 2202-2210

48. Bacci $G$, Longhi A, Briccoli $A$ et al. The role of surgical margins in treatment of Ewing's sarcoma family tumors: experience of a single institution with 512 patients treated with adjuvant and neoadjuvant chemotherapy. Int J Radiat Oncol Biol Phys 2006; 65: 766-772

49. Enneking WF, Spanier SS, \& Goodman MA. A system for the surgical staging of musculoskeletal sarcoma. Clin Orthop Relat Res 1980: 106-120

50. Chan P, Boriani S, Fourney DR et al. An assessment of the reliability of the Enneking and Weinstein-Boriani-Biagini classifications for staging of primary spinal tumors by the Spine Oncology Study Group. Spine (Phila Pa 1976) 2009; 34: 384-391

51. Boriani $\mathrm{S}$, Biagini R, De lure $\mathrm{F}$ et al. En bloc resections of bone tumors of the thoracolumbar spine. A preliminary report on 29 patients. Spine (Phila Pa 1976) 1996; 21: 1927-1931

52. Zhang Z, Hua Y, Li G et al. Preliminary proposal for surgical classification of sacral tumors. J Neurosurg Spine 2010; 13: 651-658

53. Fehlings MG, Smith SR, Zhang Z et al. Response. Journal of Neurosurgery: Spine 2010; 13: 649-650

54. Fourney DR, Rhines LD, Hentschel SJ et al. En bloc resection of primary sacral tumors: classification of surgical approaches and outcome. J Neurosurg Spine 2005; 3: 111-122

55. Zhang HY, Thongtrangan I, Balabhadra RS et al. Surgical techniques for total sacrectomy and spinopelvic reconstruction. Neurosurg Focus 2003; 15: E5

56. Varga PP \& Lazary A. Chordoma of the sacrum: "en bloc" high partial sacrectomy. Eur Spine J 2010; 19: 1037-1038

57. Varga PP \& Lazary A. Chordoma of the sacrum: "en bloc" total sacrectomy and lumbopelvic reconstruction. Eur Spine J 2010; 19: 1039-1040

58. Clarke MJ, Dasenbrock H, Bydon A et al. Posterior-only approach for en bloc sacrectomy: clinical outcomes in 36 consecutive patients. Neurosurgery 2012; 71: 357-364; discussion 364

59. Sherman CE, Rose PS, Pierce LL et al. Prospective assessment of patient morbidity from prone sacral positioning. J Neurosurg Spine 2012; 16: 51-56

60. Court C, Bosca L, Le Cesne A et al. Surgical excision of bone sarcomas involving the sacroiliac joint. Clin Orthop Relat Res 2006; 451: 189-194

61. Bergh P, Gunterberg B, Meis-Kindblom JM et al. Prognostic factors and outcome of pelvic, sacral, and spinal chondrosarcomas: a center-based study of 69 cases. Cancer 2001; 91: 1201-1212

62. Todd LT, Jr., Yaszemski MJ, Currier BL et al. Bowel and bladder function after major sacral resection. Clin Orthop Relat Res 2002: 36-39

63. Guo Y, Palmer JL, Shen $\mathrm{L}$ et al. Bowel and bladder continence, wound healing, and functional outcomes in patients who underwent sacrectomy. J Neurosurg Spine 2005; 3: 106-110

64. Guo W, Tang X, Zang J et al. A Concise and Informative Title: One-Stage Total en bloc Sacrectomy- A Novel Technique and Report of 9 Cases. Spine (Phila Pa 1976) 2013:

65. Ahmed AR. Safety margins in resection of sacral chordoma: analysis of 18 patients. Arch Orthop Trauma Surg 2009; 129: 483-487

66. Fuchs B, Dickey ID, Yaszemski MJ et al. Operative management of sacral chordoma. J Bone Joint Surg Am 2005; 87: 2211-2216

67. Angelini A \& Ruggieri P. A new surgical technique (modified Osaka technique) of sacral resection by posterior-only approach: description and preliminary results. Spine (Phila Pa 1976) 2013; 38: E185-192

68. Tomita K \& Kawahara N. The threadwire saw: a new device for cutting bone. J Bone Joint Surg Am 1996; 78: 1915-1917 
69. Osaka $\mathrm{S}$, Kondoh $\mathrm{O}$, Yoshida $\mathrm{Y}$ et al. Radical excision of malignant sacral tumors using a modified threadwire saw. J Surg Oncol 2006; 93: 312-317

70. Hugate RR, Jr., Dickey ID, Phimolsarnti R et al. Mechanical effects of partial sacrectomy: when is reconstruction necessary? Clin Orthop Relat Res 2006; 450: 82-88

71. Zhu R, Cheng $\mathrm{LM}, \mathrm{Yu} Y$ et al. Comparison of four reconstruction methods after total sacrectomy: a finite element study. Clin Biomech (Bristol, Avon) 2012; 27: 771-776

72. Tomita K \& Tsuchiya $\mathrm{H}$. Total sacrectomy and reconstruction for huge sacral tumors. Spine (Phila Pa 1976) 1990; 15: 1223-1227

73. Gokaslan ZL, Romsdahl MM, Kroll SS et al. Total sacrectomy and Galveston L-rod reconstruction for malignant neoplasms. Technical note. J Neurosurg 1997; 87: 781-787

74. Murakami H, Kawahara N, Tomita $\mathrm{K}$ et al. Biomechanical evaluation of reconstructed lumbosacral spine after total sacrectomy. J Orthop Sci 2002; 7: 658-664

75. Kawahara N, Murakami H, Yoshida A et al. Reconstruction after total sacrectomy using a new instrumentation technique: a biomechanical comparison. Spine (Phila Pa 1976) 2003; 28: 1567-1572

76. Shen $\mathrm{FH}$, Harper $\mathrm{M}$, Foster WC et al. A novel "four-rod technique" for lumbo-pelvic reconstruction: theory and technical considerations. Spine (Phila Pa 1976) 2006; 31: 13951401

77. Dickey ID, Hugate RR, Fuchs B et al. Reconstruction after Total Sacrectomy. Clin Orthop Relat Res 2005; \&NA;: 42-50

78. Wuisman $\mathrm{P}$, Lieshout $\mathrm{O}$, Sugihara $\mathrm{S}$ et al. Total sacrectomy and reconstruction: oncologic and functional outcome. Clin Orthop Relat Res 2000: 192-203

79. Ruggieri $P$, Angelini A, Pala $E$ et al. Infections in surgery of primary tumors of the sacrum. Spine (Phila Pa 1976) 2012; 37: 420-428

80. Miles WK, Chang DW, Kroll SS et al. Reconstruction of large sacral defects following total sacrectomy. Plast Reconstr Surg 2000; 105: 2387-2394

81. Glatt BS, Disa JJ, Mehrara BJ et al. Reconstruction of extensive partial or total sacrectomy defects with a transabdominal vertical rectus abdominis myocutaneous flap. Ann Plast Surg 2006; 56: 526-530; discussion 530-521

82. Garvey PB, Rhines LD, Feng $L$ et al. Reconstructive strategies for partial sacrectomy defects based on surgical outcomes. Plast Reconstr Surg 2011; 127: 190-199

83. Dasenbrock HH, Clarke MJ, Bydon A et al. Reconstruction of extensive defects from posterior en bloc resection of sacral tumors with human acellular dermal matrix and gluteus maximus myocutaneous flaps. Neurosurgery 2011; 69: 1240-1247

84. Sar C \& Eralp L. Surgical treatment of primary tumors of the sacrum. Arch Orthop Trauma Surg 2002; 122: 148-155

85. Randall RL, Bruckner J, Lloyd C et al. Sacral resection and reconstruction for tumors and tumor-like conditions. Orthopedics 2005; 28: 307-313

86. Hanna SA, Aston WJ, Briggs TW et al. Sacral chordoma: can local recurrence after sacrectomy be predicted? Clin Orthop Relat Res 2008; 466: 2217-2223

87. Hulen CA, Temple HT, Fox WP et al. Oncologic and functional outcome following sacrectomy for sacral chordoma. J Bone Joint Surg Am 2006; 88: 1532-1539

88. Atalar H, Selek H, Yildiz Y et al. Management of sacrococcygeal chordomas. Int Orthop 2006; 30: $514-518$

89. Cheng EY, Ozerdemoglu RA, Transfeldt EE et al. Lumbosacral chordoma. Prognostic factors and treatment. Spine (Phila Pa 1976) 1999; 24: 1639-1645

90. Wang J, Tang $Q$, Xie $X$ et al. Iliosacral resections of pelvic malignant tumors and reconstruction with nonvascular bilateral fibular autografts. Ann Surg Oncol 2012; 19: 40434051

91. Arkader A, Yang CH, \& Tolo VT. High long-term local control with sacrectomy for primary high-grade bone sarcoma in children. Clin Orthop Relat Res 2012; 470: 1491-1497 
92. Baratti D, Gronchi A, Pennacchioli E et al. Chordoma: natural history and results in 28 patients treated at a single institution. Ann Surg Oncol 2003; 10: 291-296

93. Simpson AH, Porter A, Davis A et al. Cephalad sacral resection with a combined extended ilioinguinal and posterior approach. J Bone Joint Surg Am 1995; 77: 405-411

94. Beadel GP, McLaughlin CE, Aljassir F et al. Iliosacral resection for primary bone tumors: is pelvic reconstruction necessary? Clin Orthop Relat Res 2005; 438: 22-29

95. Li D, Guo W, Qu H et al. Experience with wound complications after surgery for sacral tumors. Eur Spine J 2013:

96. Gunterberg B, Kewenter J, Petersen I et al. Anorectal function after major resections of the sacrum with bilateral or unilateral sacrifice of sacral nerves. Br J Surg 1976; 63: 546-554

97. Stener B \& Gunterberg B. High amputation of the sacrum for extirpation of tumors. Principles and technique. Spine (Phila Pa 1976) 1978; 3: 351-366 